\title{
THE PORT SERVICE ECOSYSTEM RESEARCH BASED ON THE LOTKA-VOLTERRA MODEL
}

\author{
Wenjuan $\mathrm{Li}^{1}$ \\ Wei Liu ${ }^{1}$ \\ $\mathrm{Xu} \mathrm{Xu^{2 }}$ \\ Zhijun Gao \\ ${ }^{1}$ College of Transport and Communications. Shanghai Maritime University, China \\ ${ }^{2}$ Business School, Shanghai Dian Ji University, China
}

\begin{abstract}
Under the new normal of China's economy, the competition among the port enterprises is not only the competition of the core competence of the port, the port industry chain or the port supply chain, but also the competition of the port service ecosystem. In this paper, the concept and characteristics of the port service ecosystem is discussed, a hierarchical model of the port service ecosystem is constructed. As an extended logistic model, Lotka-Volterra model is applied to study the competitive co-evolution and mutually beneficial co-evolution of enterprises in the port service ecosystem. This paper simulates the co-evolution of enterprises in the port service ecosystem by using MATLAB programming. The simulation results show that the breadth of the niche of the enterprises is changing with the change of the competition coefficient and the coefficient of mutual benefit in the port service ecosystem. Based on that, some proposals are put forward to ensure the healthy and orderly development of the port service ecosystem.
\end{abstract}

Keywords: the port service ecosystem, the niche breadth, competitive co-evolution, mutually beneficial co-evolution

\section{INTRODUCTION}

Since the implementation of reform and opening up in the late 1970s in China, the ports have developed rapidly and the overall capacity tends to equilibrium of supply and demand, but there are structural, regional overcapacity tendencies [1] [2]. Most of the ports along the coast have common economic hinterlands and the vicious competition in the price is growing [3]. The lack of cooperation and over-competition between ports hinders the sustainable development of ports. In addition, the infrastructure in some of China's ports, especially the inland ports, cannot meet the needs of largescale and diversified goods, and the problem of low degree of information in China's ports also affects the communication among different departments and results in lower efficiency and customer satisfaction.
The establishment of the port service ecosystem can effectively promote the connection between ports and the relevant enterprises, and also can contribute to information exchange and knowledge sharing. The competition of the port enterprises will be the competition of the ecosystem which regards the port enterprise as a core. It's an important goal of "the Belt and Road Initiatives" project to promote the development of align national and regional economic and trade. Ports are important nodes of the 21st-Century Maritime Silk Road. That will create a favourable political and economic environment for the construction of the port service ecosystem, and ports will usher in new development opportunities [4].

The term "ecosystem" was first used in a publication by British ecologist Arthur Tansley. He later refined the term, describing it as the whole system, including not only the 
organism-complex, but also the whole complex of physical factors forming what we call the environment. After that, the concept of ecosystem was introduced into business research. As a famous American strategic management scientist, Moor put forward the concept of "business ecosystem" in Harvard Business Review [5]. He explained the new competition among enterprises, the symbiosis and the way of sustainable development of enterprises and environment. Moore pointed out that the enterprise ecosystem is an economic community based on interaction between organization and individual in his book "The Death of Competition" [6].

Zhao et al. discussed the basic structure of the enterprise ecosystem, analyzed the characteristics and the evolution of the enterprise ecosystem, and used the logistic model to describe the process of the evolution of the enterprise ecosystem [7]. Meanwhile, the study put forward the strategy of enterprise ecosystem evolution in according with the above. The model of tourism industry ecosystem was constructed from five aspects: material and energy source, Producers, consumers, decomposers and ecological environment [8]. Zhao summarized the concept of port strategic synergy, systematically studied the horizontal strategic cooperation and vertical strategic coordination, and then put forward the strategic integration of alliance of ports in Zhejiang province in China [9].

In 2016, China Merchants Port proposed to build a comprehensive port service ecosystem, the Shanghai Port Group also proposed to build a smart port service ecosystem in China. However, there are few literatures on the study of port service ecosystem. This paper will study the concept of port service ecosystem, hierarchical model and co-evolution of the port service ecosystem.

\section{CONNOTATION AND CHARACTERISTICS OF THE PORT SERVICE ECOSYSTEM}

\section{THE CONCEPT OF THE PORT SERVICE ECOSYSTEM}

Combined the concept of business ecosystem with enterprise ecosystem, port service ecosystem can be defined. In order to ensure its sustainable development, port enterprises integrate the upstream and downstream port industry chain and connect the various port elements .Port service ecosystem is a sort of economic association that is formed by ports and related organizations. Its members include port enterprises, shipping companies, freight forwarding companies, shippers, market intermediaries, etc., to a certain extent, also include competitors. These members form value chains, and the interweaving of different chains forms a network of values. Material, energy and information flow through the value network among members [10]. The members of port service ecosystem make rational use of resources and improve the work efficiency and the ability to work together, so that the port service ecosystem is in a relatively stable dynamic equilibrium in a certain period of time and provides quality services to customers.

\section{THE COMPOSITION OF THE PORT SERVICE ECOSYSTEM}

In ecology, the ecosystem is divided into four levels as individual, population, community and ecosystem. Enterprise ecosystem, in analogy to natural ecosystem, consists of a variety of biological members including biological and non-biological components which are mutually dependent. The main biological members of port service ecosystem are port enterprises and populations formed by homogeneous enterprises $\sum a_{i}$ (other ports within the region), customers $\sum b_{i}$ (shippers, shipping companies, etc.), port service providers $\sum c_{i}$ (carriers, stevedoring firms, warehousing enterprises, logistics service providers, port equipment maintenance, etc. ), market intermediaries $\sum d_{i}$ (freight forwarders, customer agents, shipping agents, shipping exchanges, port and shipping trading sites and platforms, etc.), financial institutions $\sum e_{i}$ and investors $\sum f_{i}$ and so on [11] [12]. In the external environment of enterprise ecosystem, there are a variety of non-biological factors, including political ecological factors $\sum A_{i}$, economic ecological factors $\sum B_{i}$, social ecological factors $\sum C_{i}$, natural ecological factors $\sum D_{i}$, etc. There are two types of relationship between populations. One is vertical relationship and the other is horizontal relationship. Port service providers, customers, port market intermediaries, etc. are vertical relations, while competitors, government departments, research institutions, other stakeholders, and other related industries or departments are horizontal relations [13].

The function of the port service ecosystem can be expressed as:

The port service ecosystem $=\mathrm{F}$ (biological components, non-biological components)

$=F\left(\sum a_{i}, \sum b_{i}, \sum c_{i}, \sum d_{i}, \sum e_{i}, \sum f_{i}, \cdots, \sum A_{i}, \sum B_{i}, \sum C_{i}, \sum D_{i}, \cdots\right)$.

In addition, the port service ecosystem also includes the relevant institutions which set standards and relevant government departments (maritime, customs, border inspection, etc.), association representing the consumers (ship-owners' associations, shippers' associations) and suppliers' associations (logistics associations, etc.) and so on.

\section{THE HIERARCHICAL MODEL AND BUSINESS AREA OF THE PORT SERVICE ECOSYSTEM}

If natural ecological system centered on plants and animals, and the port service ecosystem centred on port enterprises. From the aspect of the tightness and importance of biological members, the port service ecosystem can be divided into three levels as the core ecosystem, the expansion ecosystem and the complete port service ecosystem. The core of the port service ecosystem includes port enterprises, port service suppliers and port service customers. The expansion layer includes the suppliers of port service suppliers, customers of port service customers, and related industries. The simplified hierarchical model of the port service ecosystem is shown in Fig. 1. 


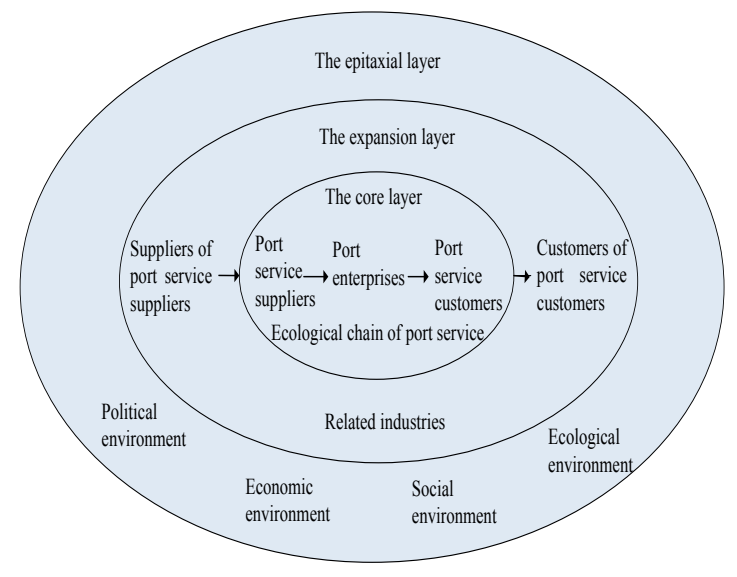

Fig. 1. The hierarchical model of the port service ecosystem

The main business of port enterprises is terminal operation and management. In recent years with the needs of development, the business of port enterprises extends to modern logistics, trade, consulting, information, insurance, finance, tourism and leisure, and others. The business domain of the port service ecosystem is shown in Fig.2 [14].

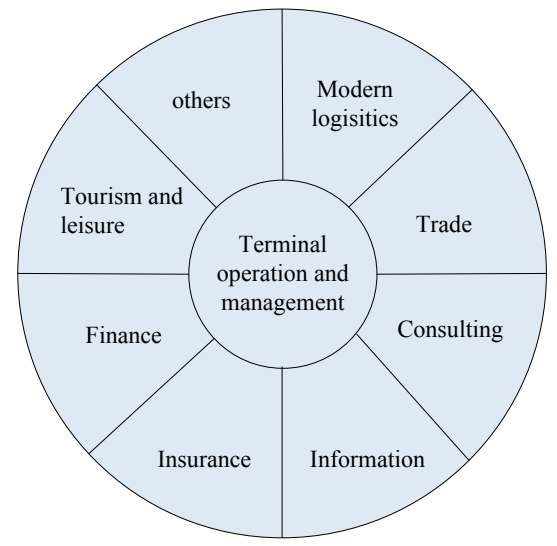

Fig. 2. The business domain of the port service ecosystem

\section{CHARACTERISTICS OF THE PORT SERVICE ECOSYSTEM}

The existence of a series of interactions among members is not only one of the main characteristics of the biological ecosystem, but also the basic condition for the survival of species. Most of the interactions in the ecosystem are indirect, and the impact of specific interactions may be far greater than the impact on both sides of the interaction. In the interactive route, the core species is usually the node that is necessary for interaction. Port enterprises are the core species of port ecology, and the interaction of port enterprises with other members of the ecosystem (including both direct and indirect interaction) is an important feature of the port service ecosystem.

Similar to the biological ecosystem, the business ecosystem also has a large number of loosely connected participants. Each participant gets their own required living resources from the other participants. Co-evolution is a kind of objective existence in the port service ecosystem, which is another important feature of the port service ecosystem. It is impractical for the port enterprises to develop alone if port enterprises have to develop. Port enterprises need to understand and grasp the relationship between the relevant enterprises and departments correctly and comprehensively, cooperate with other logistics service suppliers scientifically and reasonably, and ensure that these enterprises make a supplementary contribution, which thereby can enhance their own competitiveness and create more value for customers.

Another feature of the port service ecosystem is openness. Previously, the internal and external boundaries of enterprises are clear, but now the boundaries of enterprise and industries in the port service ecosystem become blurred and openness becomes more obvious. Therefore who can meet customer needs and create value for customers can be allowed in the port service ecosystem, otherwise they will be refused by the port service ecosystem.

\section{THE CONNOTATION OF CO-EVOLUTION OF PORT SERVICE ECOSYSTEM}

\section{CONCEPT OF THE PORT SERVICE ECOSYSTEM SYNERGY}

As a system theory, synergy has the characteristics of universality. The port service ecosystem is a port-based ecosystem, so synergy is applicable to study on the port service ecosystem. Port strategic synergy includes port horizontal strategic synergy and port vertical strategic synergy. Port horizontal strategic synergy refers to the regional port alliance of two or more port enterprises that are complementary to each other and prevent vicious competition to improve regional port competitiveness in the same area, which is mainly arterial and branch port alliance and hub port alliance. Port vertical strategic synergy refers that the port enterprises, upstream and downstream enterprises and the relevant units or departments form a port supply chain with the feature of rationalization of business and risk-sharing. Port service ecosystem synergy not only refers to the port strategy synergy, but also includes the synergy between elements of the enterprise (member) within the port service ecosystem, between the enterprise (member) and the enterprise (member), and between the enterprise (member) and the environment.

\section{THE NECESSITY OF STUDYING CO-EVOLUTION OF PORT SERVICE ECOSYSTEM}

Port enterprise operation environment is constantly changing, and growing problems are becoming increasingly complex. Since challenges, uncertainties, risks, and crisis exist side by side, it is very necessary and beneficial to do 
a systematic analysis of the development of port enterprises from the perspective of biological co-evolution. Co-evolution is an important feature of biological evolution, which emphasizes the collaboration between different populations to improve the efficiency of population use of environmental resources and improve the viability of the population. The coordinated development between enterprises constitutes the basic conditions for the survival and development of enterprises, and the evolution of an enterprise depends not only on the firm itself, but also on the evolution of other members of the ecosystem. In complex and volatile business environment, it is blind to only care about the business development of their own business. Therefore, the port enterprises need to pay close attention to the changes in other port enterprises, port service suppliers, port service customers (shipping companies, land transport companies, shippers and so on), port industry, political environment, economic environment, social environment, and natural environment of port business, and also need to make the appropriate adjustments according to these changes, to improve the adaptability to external markets [15]. Thus, it is necessary to study the co-evolution of the port service ecosystem.

\section{THE CONNOTATION OF CO-EVOLUTION OF THE PORT SERVICE ECOSYSTEM}

The co-evolution of the port service ecosystem includes the co-evolution within the enterprises (members) of the port service ecosystem, the co-evolution between the enterprises (members), and the co-evolution between the enterprises (members) and the external environment. The co-evolution between enterprises is discussed in this paper, which includes independent evolution, competitive co-evolution, amensalism co-evolution, commensalism co-evolution, mutually beneficial co-evolution and so on. Amensalism co-evolution can be viewed as a special case of competitive co-evolution and partial cooperative co-evolution can be viewed as a special case of mutually beneficial co-evolution (as shown in 5.1.2), thus the competitive co-evolution model and the mutually beneficial co-evolution model is focus on in this paper.

\section{CONSTRUCTION AND SIMULATION OF COOPERATIVE EVOLUTION MODEL OF THE PORT SERVICE ECOSYSTEM}

In ecological research, Lotka-Volterra model can be applied to the co-evolution among organisms, and can also be used to study the relationship among biological population group [16] [17].In this part, this model is used to analyze the cooperative evolution mechanism between different populations of the port service ecosystem.

The ecological niche can be used to describe the cooperative evolution among enterprises and enterprises, enterprises and resources. The ecological niche refers to the space and time position and function of each individual or population in population or community. The niche size of an enterprise is the width of the niche or niche breadth, which is the sum of all kinds of resources that can be utilized by the enterprise. If the niche breadth of the enterprise is larger, the competitiveness of the enterprise will be stronger. Niche overlap is the phenomenon that two or more enterprises ofthe same ecological niche share or compete for common resources. Due to the limited resources, when a number of enterprises coexist in the port ecological niche and if their niche overlaps, there will be competition for resources.

\section{CO-EVOLUTIONARY MODELLING}

Modelling assumption:

(1)Assuming that the external environment of the port service ecosystem is unchanged, that is, without considering the impact of the external environment on the co-evolution between enterprises.

(2)Assuming that all kinds of resource elements in the port service ecosystem are constant, restricted by ecological factors $E_{i}$.

(3)Assuming that there are only two enterprises in the port service ecosystem, for enterprise 1 and enterprise 2 . When enterprise 1 and enterprise 2 survive alone, following the law of Logistic.

\section{Competitive co-evolution}

$N_{1}, N_{2}$ indicate the niche breadth of enterprise 1 and enterprise 2 respectively. $t$ represents time variable. $r_{1}$ 、 $r_{2}$ indicate that the maximum growth rate of the niche of two companies living alone respectively. $\alpha_{1}$ indicates that competition coefficient of enterprise 1 to enterprise 2 , that is, inhibitory effect of enterprise 2 on $1,0<\alpha_{1}<1$. $\alpha_{2}$ indicates that competition coefficient of enterprise 2 to enterprise 1,that is, inhibitory effect of enterprise 1 on 2, $0<\alpha_{2}<1 . K_{1}, K_{2}$ indicate the maximum environmental capacity or environmental load of two enterprises respectively. Competitive co-evolutionary model is established as shown in equation (1):

$$
\left\{\begin{array}{l}
\frac{d N_{1}}{d t}=r_{1} N_{1}\left(1-\frac{N_{1}}{K_{1}}-\frac{\alpha_{1} N_{2}}{K_{1}}\right) \\
\frac{d N_{2}}{d t}=r_{2} N_{2}\left(1-\frac{N_{2}}{K_{2}}-\frac{\alpha_{2} N_{1}}{K_{2}}\right)
\end{array}\right.
$$

In the formula (1), $\frac{N_{1}}{K}$ is the resource space of the enterprise $1, \frac{\alpha_{1} N_{2}}{K_{1}}$ is the resource space of enterprise 2 seizing 1. $1-\frac{N_{1}}{K}-\frac{\alpha_{1} N_{2}}{K}$ is the residual resource space that can be used by enterprises. $\alpha_{1}, \alpha_{2}$ reflect the degree of niche overlap. The more the value, the higher degree of niche overlaps of the two companies, the little the value, the lower degree of niche overlaps. When the values of $\alpha_{1}$ and $\alpha_{2}$ are infinitely close to 1 , the niche of the two enterprises tends to be completely overlap. When the values of $\alpha_{1}$ and $\alpha_{2}$ are infinitely close to 0 , the niche of the two enterprises is close to complete separation. In 
the formula (1), if $\alpha_{1}=0$ and $0<\alpha_{2}<1$, or $0<\alpha_{1}<1$ and $\alpha_{2}=0$, the model is an amensalism co-evolution model.

\section{Mutual benefit co-evolution model}

Enterprises are not only competitive, but also certainly cooperation with each other in the port service ecosystems. In the process of providing transportation service, logistics service or supply chain service to customers, the mutual beneficial cooperation between the firms in the port service ecosystem is indispensable. Mutually beneficial cooperation is the basis of win-win or multi-win between enterprises and also the embodiment of the overall efficiency of the port service ecosystem. Mutual benefit co-evolution model can solve the problem of how to cooperate effectively and realize the co-evolution between enterprises.

$\beta_{1}$ represents the niche mutual benefit coefficient of enterprise 1 to enterprise $2,0<\beta_{1}<1, \beta_{2}$ represents the niche mutual benefit coefficient of enterprise 2 to enterprise 1 , $0<\beta_{2}<1, K_{1}, K_{2}$ indicate the maximum environmental capacity or environmental load of two enterprises respectively. Using mathematical model to establish mutually beneficial co-evolution model as shown in equation (2):

$$
\left\{\begin{array}{l}
\frac{d N_{1}}{d t}=r_{1} N_{1}\left(1-\frac{N_{1}}{K_{1}}+\frac{\beta_{1} N_{2}}{K_{2}}\right) \\
\frac{d N_{2}}{d t}=r_{2} N_{2}\left(1-\frac{N_{2}}{K_{2}}+\frac{\beta_{2} N_{1}}{K_{1}}\right)
\end{array}\right.
$$

There is a mutually beneficial relationship among enterprises, which create synergistic effects in the port service ecosystem. In the formula (2), $\frac{\beta_{1} N_{2}}{K_{2}}$ is the resource space that the enterprise 2 brings to the ${ }^{K_{2}}$ enterprise 1 through mutually beneficial relationship. $1-\frac{N_{1}}{K_{1}}+\frac{\beta_{N} N_{2}}{K_{2}}$ represents the remaining resource space that $K_{1} \quad K_{2}$ enterprise 1 can use. In the equation (2), when $\beta_{1}=0$ and $0<\beta_{2}<1$,or $0<\beta_{2}<1$ and $\beta_{2}=0$, then the model is a commensalism co-evolution model.

\section{SIMULATION AND RESULTS ANALYSIS}

\section{Competitive co-evolutionary simulation}

Based on the MATLAB software, four cases are simulated as follows.

When $K_{1}=K_{2}=100, r_{1}=r_{2}=1, \alpha_{1}=0.1, \beta_{2}=0.4$, the niche breadth of enterprise 1 and enterprise 2 is shown in Figure 3. When $K_{1}=K_{2}=100, r_{1}=r_{2}=1, \alpha_{1}=0.3, \alpha_{2}=0.9$, the niche of enterprise 1 and enterprise 2 is shown in Fig4. When $K_{1}=K_{2}=100, r_{1}=r_{2}=1, \alpha_{1}=0.5, \alpha_{2}=0.9$, the niche of enterprisel and enterprise 2 is shown in Figure 5. When $K_{1}=K_{2}=100, r_{1}=r_{2}=1, \alpha_{1}=0, \alpha_{2}=0.5$, the niche of enterprise 1 and enterprise 2 is shown in Fig. 6.

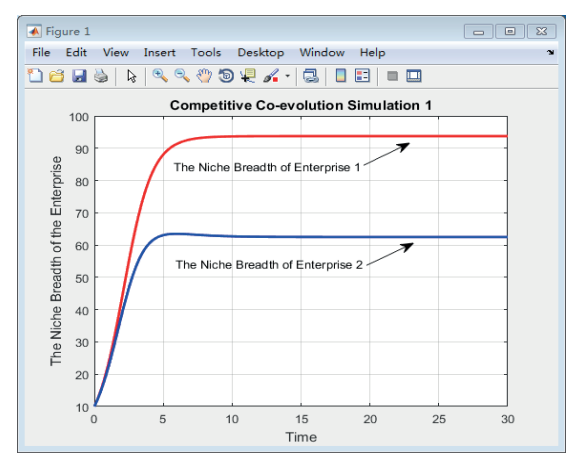

Fig. 3. Competitive Co-evolution Simulation 1

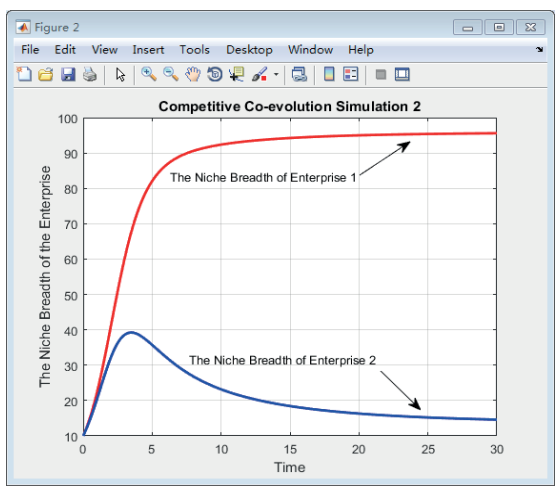

Fig. 4. Competitive Co-evolution Simulation

As can be seen from Fig.3 to Fig.6,when $K_{1}=K_{2}, r_{1}=r_{2}$, $\alpha_{1}<\alpha_{2}$, then $0<\mathrm{N}_{2}<\mathrm{N}_{1}<100$; As can be seen from Fig.3 and Fig.4, When $K_{1}, K_{2}, r_{1}, r_{2}$ do not change, $\alpha_{1}, \alpha_{2}$ increase at the same time, then $N_{1}, N_{2}$ both decreases; As can be seen from Fig.4 and Fig.5, When $K_{1}, K_{2}, r_{1}, r_{2}, \alpha_{2}$ do not change, $\alpha_{1}$ increases, then $N_{1}$ decreases and $N_{2}$ increases; As can be seen from Fig.5 and Fig.6, When $K_{1}, K_{2}, r_{1}, r_{2}$ do not change, $\alpha_{1}, \alpha_{2}$ decrease at the same time, then $N_{1}, N_{2}$ both increase, and while $\alpha_{1}=0, N_{1}$ approaches to 100.In other words, it can be seen from the figures that if the competition coefficient is bigger, the niche breadth decrease more quickly in the port service ecosystem. The smaller the competition coefficient, the slower the niches breadth reduces. The competition coefficient is proportional to the reduction of the overall niche of the ecosystem, which reflects the synergies between the enterprises because of the competitive relationship.

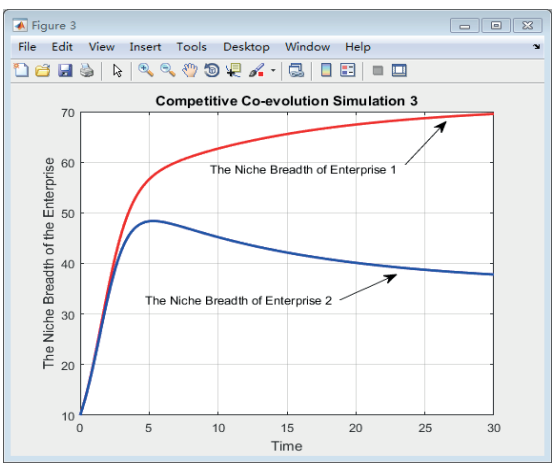

Fig. 5. Competitive Co-evolution Simulation 3 


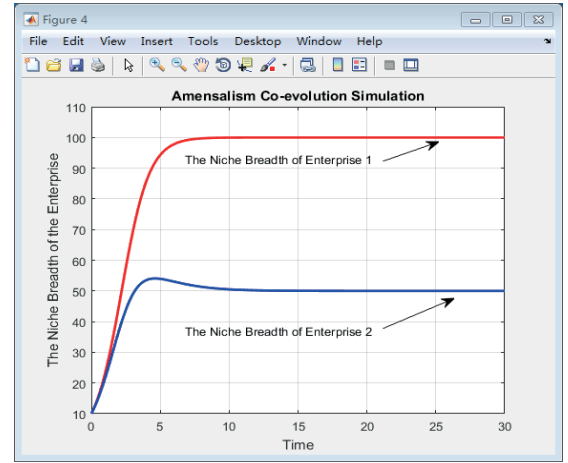

Fig. 6. Amensalism Co-evolution Simulation

\section{Mutual benefit co-evolutionary simulation}

When $K_{1}=K_{2}=100, r_{1}=r_{2}=1, \beta_{1}=0.3, \beta_{2}=0.4$, the niche breadth of enterprise 1 and enterprise 2 is shown in Fig.7. When $K_{1}=K_{2}=100, r_{1}=r_{2}=1, \beta_{1}=0.3, \beta_{2}=0.8$, the niche breadth of enterprise 1 and enterprise 2 is shown in Figure 8. When $K_{1}=K_{2}=100, r_{1}=r_{2}=1, \beta_{1}=0.7, \beta_{2}=0.8$, the niche breadth of enterprise 1 and enterprise 2 is shown in Fig. 9. When $K_{1}=K_{2}=100, r_{1}=r_{2}=1, \beta_{1}=0, \beta_{2}=0.5$, the niche breadth of enterprise 1 and enterprise 2 is shown in Fig. 10.

As can be seen from Fig. 7 to Fig. 10, when $K_{1}=K_{2}, r_{1}=r_{2}$, $\beta_{1}<\beta_{2}$, then $100<\mathrm{N}_{1}<\mathrm{N}_{2}$; As can be seen from Fig. 7 and Fig. 8 , When $K_{1}, K_{2}, r_{1}, r_{2}, \beta_{1}$ do not change, $\beta_{2}$ increases, then $N_{1}, N_{2}$ both increase and $N_{1}$ increases faster than $N_{2}$; As can be seen from Fig.7 and Fig. 9, When $K_{1}, K_{2}, r_{1}$, $r_{2}$ do not change, $\beta_{1}$ and $\beta_{2}$ both increase, then $N_{1}$ and $N_{2}$ both increase; As can be seen from Fig. 9 and Fig. 10, When $K_{1}, K_{2}, r_{1}, r_{2}$ do not change, $\beta_{1}$ and $\beta_{2}$ both decrease, then $N_{1}, N_{2}$ both decreases and while $\beta_{1}=0, N_{1}$ approaches to 100.The four figures illustrate that while the mutual benefit coefficient is bigger, the larger the niche scale of the port service ecosystem, and the smaller the coefficient of mutual benefit, the smaller the niche scale of the whole ecosystem. The coefficient of mutual benefit is proportional to the growth of the overall niche of the ecosystem, which reflects the synergy between enterprises because of the mutually beneficial relationships.

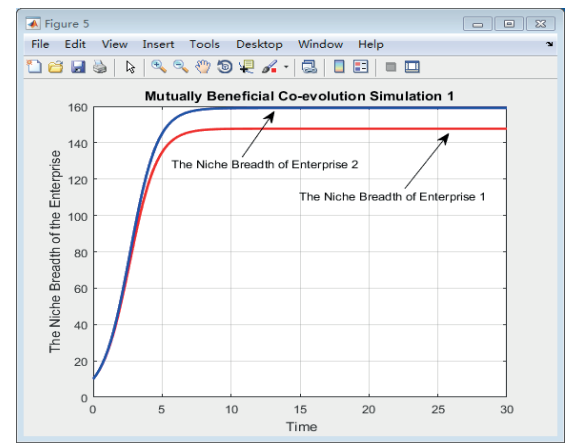

Fig. 7. Mutually Beneficial Co-evolution Simulation 1

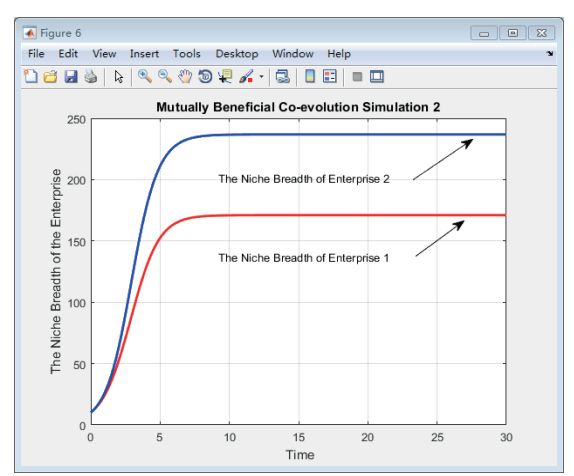

Fig. 8. Mutually Beneficial Co-evolution Simulation 2

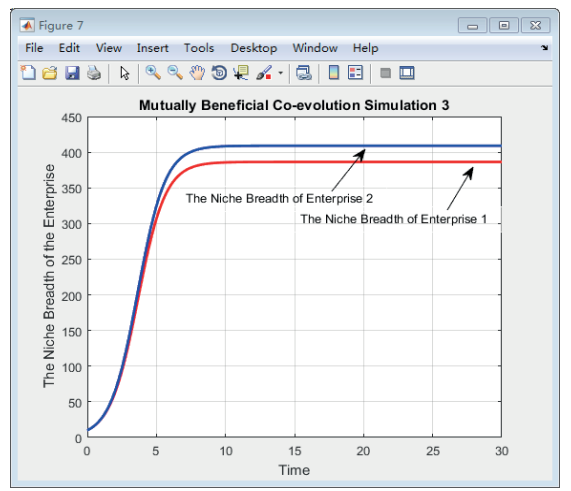

Fig. 9. Mutually Beneficial Co-evolution Simulation

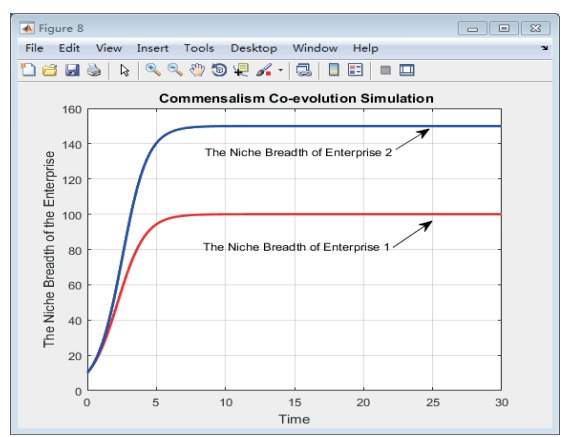

Fig. 10 Commensalism Co-evolution Simulation

With the rapid development of global economy, the increase of uncertainty and the intensification of competition, it is difficult for the enterprises in the port service ecosystem to cope with the fierce competition and meet the needs of users on its own. If the enterprise niche overlaps, it will inevitably increase the use of resources competition. If there is a trend of niche separation, the resource competition between each other can be reduced. In order to obtain the maximum interests of the whole ecosystem, the port service ecosystem enterprises should try to reduce the formation of niche overlap, niche complementary and cooperation, and ultimately achieve the development from the pursuit of their own interests to maximize the pursuit of win-win or even win-win cooperation in the direction of cooperation, and co-evolution. 


\section{EXTENSION OF COMPETITIVE CO-EVOLUTION MODEL}

\section{Extension of competitive co-evolution model}

It is assumed that there are only two enterprises in the ecosystem. But in practice, there are a large number of enterprises. The model (1) is extended to construct a co-evolution model for a number of competitive enterprises in the ecosystem, such as formula (3).

$$
\frac{d N_{i}}{d t}=r_{i} N_{i}\left(1-\frac{N_{i}}{K_{i}}-\sum_{j=1}^{n} \frac{\alpha_{i j} N_{j}}{K_{i}}\right), i \neq j
$$

$N_{i}$ and $N_{j}$ represent the niche width of enterprise $i$ and enterprise $j$, respectively. $r_{i}$ indicates the maximum growth rate of the niche width when the enterprise $i$ is alone. $K_{i}$ indicates the environmental capacity of the niche of enterprise $i$. $\alpha_{i j}$ indicates the competition coefficient that the niche of enterprise $i$ competes with enterprise $j$.

\section{Extension of the mutually beneficial co-evolutionary} model

$K$ indicates the environmental capacity of the niche of enterprise $j$. There are a number of enterprises with mutually beneficial relations in the port service ecosystem. The model (2) is extended to construct a co-evolutionary model which is suitable for the port service ecosystem, such as formula (4).

$$
\frac{d N_{i}}{d t}=r_{i} N_{i}\left(1-\frac{N_{i}}{K_{i}}+\sum_{j=1}^{n} \frac{\beta_{i j} N_{j}}{K_{j}}\right)
$$

\section{Extension of competitive-mutually beneficial} co-evolutionary model

In fact, enterprises are no longer just a competitive relationship or a mutually beneficial relationship, but a competitive relationship and a mutually beneficial at the same time in the port service ecosystem. By integrating the competitive co-evolution and the mutually beneficial co evolutionary model, we can get the co-evolution model, such as (5). The symbolic meaning of the model is the same as before.

$$
\frac{d N_{i}}{d t}=r_{i} N_{i}\left(1-\frac{N_{i}}{K_{i}}-\sum_{j=1}^{n} \frac{\alpha_{i j} N_{j}}{K_{i}}+\sum_{j=1}^{n} \frac{\beta_{i j} N_{j}}{K_{j}}\right), i \neq j
$$

According to the formula (5), the synergistic effect is determined by the parameters of $\alpha_{i j}, \beta_{i j}, K_{i}, K_{j}$. That is to say the synergistic effect is determined by the competition coefficient, the coefficient of mutual benefit, and the limiting capacity of the enterprise niche. Suppose $\gamma_{s}=\frac{\beta_{i}}{K_{i}}-\frac{\alpha_{i}}{K_{i}}$, When $\gamma_{i j}>0$ is used, the niche breadth of the ${ }^{K_{j}} K_{i}$ mutual benefit relationship between the enterprises is growth than that of the niche overlap caused by the competition, which makes the overall synergy of the port service ecosystem increase.
When $\gamma_{i j}=0$, mutual benefit influence and competition influence cancels each other and the whole ecological effect of port service ecosystem is unchanged. When $\gamma_{i j}<0$, the impact of competition is greater than the benefits brought by the cooperation of mutual benefit. Because of the overlap, the overall size of niche width of the Port enterprise ecosystem decreases. Under the pressure of competition, the enterprises in the port service ecosystem constantly tap resources, enhance their competitiveness and expand their niche.

The model (5) is of great significance for the accurate representation of the cooperative evolution behaviour of firms in the port service ecosystem. Meanwhile, there is a competition and mutually beneficial cooperation between enterprises in the port service ecosystem. In order to survive and develop, enterprises have to improve their competitiveness, improve the utilization of resources, and expand their niche breadth.

\section{ADVICE FOR THE DEVELOPMENT OF THE PORT SERVICE ECOSYSTEM}

\section{ESTABLISHMENT OF THE PORT SERVICE ECOSYSTEM}

In order to set up a port service ecosystem with itself as the core, large-scale port enterprises can select vertical or horizontal strategy. They can choose right companies as their logistics service provider to form an industry cluster combining core enterprises with affiliated ones. In addition, the port enterprises can establish a long-term cooperation, strengthen the contact and communication with relevant companies, departments in business and technology to build an ecological chain of port service. Under the new normal of China's economy, port enterprises can cooperate with each other by forming strategic alliances or partnerships, and upgrading production efficiency, utilization rate and service quality to adapt to periodic and regional surplus in port capacity. In a whole, the foundation of port service ecosystem will be well improved.

\section{THE ROLE AS THE KEYSTONE}

The roles acted by members in the port service ecosystem can be designated into four types, which are keystone, dominator, hub landlord and niche [18]. In accordance with their different roles, they boast distinct influence on the port service ecosystem, varying their opportunities to benefit from the ecosystem. The keystone enterprise has significant impact on the stability, variety and productivity of the ecosystem. The port enterprise is the keystone species of the port ecosystem, which should exploit their key status in the ecosystem to create value and share merits with others, then make a proper balance between value creation and value occupation to achieve synergy effect $[19,20]$. The port enterprise should not take too much value from the ecosystem, otherwise it 
will be transformed into hub landlord, which is bad for the health of the port service ecosystem and not conducive to synergy evolution.

\section{K-STRATEGY}

In order to ensure the sustainable development of ecosystem and maintain the species variety, the port service ecosystem needs to keep in continuous contacting with the exterior aiming at the exchange of materials, information and energy. New companies are encouraged to be absorbed into not only the ecosystem even into the ecological chain. However, the number of the companies s involved is not the more the better owing to the environmental limitation. Consequently, it will do harm to the progress of the ecosystem if it outweighs the limitation. Ecological strategies are formed in the process of environmental adaptation and biological evolution. During the competition, those who choose R-strategy spend most energy on reproduction while those who choose K-Strategy prefer to improve their living rate. Instead of relying on the expansion of production scale only or implementing low-cost tactic, the enterprises in the ecosystem should improve their service, develop core technologies and exploit their creativity, transforming from the quantity essence to the quality one to hold their status and benefits.

\section{A PLATFORM FOR INTERACTION}

With the development of the Internet and large data, the global economy into the "Internet +" era, in which the accuracy of information, timeliness and sharing requirements have never been so high, so it's pretty imminent to build an information sharing platform in the port service ecosystem [21]. The open platform not only facilitates the exchange and interaction among the members of the ecosystem, maintains the relative stability of the ecosystem, but also facilitates the co-evolution of the members of the ecosystem and the external environment. What's more, its establishment is beneficial to attract more enterprises to join the ecosystem, bring new dynamics to the ecosystem.

\section{CONCLUSION}

This paper constructs competitive co-evolution and mutual beneficial co-evolution models of the port service ecosystem. The models are solved, and the results are analyzed. On the basis of these, the competition and cooperation co-evolution model of port service ecosystem is constructed. How cooperative effect of the port service ecosystem is determined by the capacity of the resources and the coefficient of competition and mutual benefit. The co-evolutionary models are of great significance for the accurate representation of the co-evolution of the port service ecosystem.

Under the new normal of China's economy, the market features and operational environment of China's ports have changed a lot. The members should take measures to reduce the competition coefficient and increase the coefficient of mutual benefit. When the number of the enterprises in the port service ecosystem exceeds 2 , synergy effect is only expressed in the model rather than the simulation, which need to be studied. Apart from that, actual examples aren't associated with the theory, which also should be studied further.

\section{ACKNOWLEDGEMENTS}

The authors are thankful to the National Natural Science Foundation, the Ministry of Education of China, and Shanghai Maritime University Graduate Student Innovation Fund for providing support for this research (Grant\#71272219; 11YJA630067; 2013ycx057, respectively).

\section{REFERENCES}

1. Wei Liu, Wenjuan $\mathrm{Li}$, and $\mathrm{Xu} \mathrm{Xu}$, The Analysis of the PPP Financing Model Application in Ports of China. Journal of Coastal Research. 2015, 73(spl): 4-8, DOI: 10.2112/ SI73-002.1

2. Shanqing Zhu, Jianxin Chen. Review of coastal ports infrastructure in 2015. China Ports, 2016, (5): 9-11. DOI:10.3969/j.issn.1006-124X.2016.05.004

3. Xin Shi, Huan Li. Developing the port hinterland: Different perspectives and their application to Shenzhen Port, China. Research in Transportation Business \& Management, 2016. 6. DOI: 10.1016/j.rtbm.2016.05.004

4. Guohua Zhang. The Road of Ports transformation and upgrading under the strategy of "the Belt and Road". China National Conditions and Strength. 2015, (3): 17-19. DOI: 10.3969/j.issn.1004-2008.2015.03.006

5. Moore, J. F. Predators and prey: the new ecology of competition. Harvard Business Review. 1993, 71(3), 75-83.

6. Moore, J. F. The Death of Competition: Leader and Strategy in the Age of Business Eco-systems. New York: Harper Business Press, 1996.

7. Shukuan Zhao, Taoqun Hao and Jinjin Li. Analysis of enterprise ecosystem evolution based on logistic model. Industrial Technology Economics, 2008, 27(10), 70-72. DOI:10.3969/j.issn.1004-910X.2008.10.021.

8. Yong Ma and Chan Zhou. Construction and Management Innovation of Tourism Industry Ecosystem. Journal of Wuhan University, 2014, (4): 5-9. DOI: 10.3969/j. issn.1009-2277.2014.04.001.

9. Na Zhao. Port Strategic Coordination. Zhejiang University Press, 2012. 
10. Cebrian J. Energy flows in ecosystems. Science, 2015, 349: 1053-1054. DOI:10.1126/science.aad0684

11. Bin Hu. The Dynamic Evolution and Operation of Enterprise Ecosystems. Hohai University, 2006.

12. Flint D J, Lusch R F, Vargo S L. The supply chain management of shopper marketing as viewed through a service ecosystem lens. International Journal of Physical Distribution \& Logistics Management, 2014, 44(1/2): 23-38. DOI: 10.1108/IJPDLM-12-2012-0350.

13. Chen, Jihong, et al. Operational Efficiency Evaluation of Iron Ore Logistics at the Ports of Bohai Bay in China: Based on the PCA-DEA Model. Mathematical Problems in Engineering. 2016(1), 1-13. DOI: 10.1155/2016/9604819

14. Zou, De Ling, M. Xu, and C. J. Zheng. "The Evaluation and Analysis on Port Service Development - As Ningbo and Shanghai Port for Example."Advanced Materials Research, 2013, 712-715: 2986-2990. DOI:10.4028/www.scientific.net/ AMR.712-715.2986.

15. Ye Caihong, Dong Xinping, Zhuang Peijun. Study on Resources Integration Mechanism Model in Collaborative Development of Harbor Clusters. Logistics technology. 2016, (6): 81-85. DOI:10.3969/j.issn.1005-152X.2016.06.018

16. Wei Wang. Based on Lotka-Volterra Model of Chengdu Multi-Airport System. Logistics Engineering and Management. 2015, 0(9): 177-179. DOI:10.3969/j. issn.1674-4993.2015.09.069.

17. Ruifrok J L, Janzen T, Kuijper D P, et al. Cyclical succession in grazed ecosystems: the importance of interactions between different-sized herbivores and different-sized predators. Theoretical Population Biology, 2015, in press: 31-39. DOI: 10.1016/j.tpb.2015.02.001

18. Iansiti M and Levien R. The Keystone Advantage: What the New Dynamics of Business Ecosystems Mean for Strategy, Innovation, and Sustain ability. Future Survey, 2004, 20(2): 88-90. DOI: 10.5465/AMP.2006.20591015

19. Zhijun Gao, shan liu .Study on Value Creating in Service Ecosystem Based on Service Dominated Logic. Service Science and Management. 2017,6 : 83-97. DOI: 10.12677/ SSEM.2017.62012

20. Shiyuan Zheng, R.R. Negenborn. Price negotiation between supplier and buyer under uncertainty with fixed demand and elastic demand. International Journal of Production Economics. 2015-06-01. DOI: 10.1016/j.ijpe.2015.05.024.

21. Waller M A, Fawcett S E. Data Science, Predictive Analytics, and Big Data: A Revolution That Will Transform Supply
Chain Design and Management. Journal of Business Logistics, 2013, 34(2): 77-84. DOI: 10.1111/jbl.12010.

\section{CONTACT WITH THE AUTHORS}

\author{
Wenjuan Li \\ Wei Liu \\ Zhijun Gao
}

College of Transport and Communications Shanghai Maritime University

NO.1550 Haigang Ave

Shanghai 201306

ChINA

Xu Xu

Business School ,Shanghai Dian Ji University

NO.1350 Ganlan Road, Shanghai 201306

China 